\title{
Impact of Body Composition on Prognosis and Dose-Limiting Toxicities on Metastatic Colorectal Cancer
}

\author{
David da Silva Dias ${ }^{1,2 * t}$, Mafalda Machado ${ }^{3}$, Carolina Trabulo ${ }^{2,4 t}$, Beatriz Gosálbez ${ }^{1 \dagger}$ and \\ Paula Ravasco $2,5,6+$
}

\begin{abstract}
${ }^{1}$ Medical Oncology Department, Centro Hospitalar Universitário do Algarve, Faro, Portugal, ${ }^{2}$ Centre for Interdisciplinary Research in Health, Universidade Católica Portuguesa, Lisbon, Portugal, ${ }^{3}$ Radiology Department, Centro Hospitalar Universitário do Algarve, Faro, Portugal, ${ }^{4}$ Medical Oncology Department, Centro Hospitalar Barreiro Montijo, Barreiro, Portugal, ${ }^{5}$ Católica Medical School, Universidade Católica Portuguesa, Lisbon, Portugal, ${ }^{6}$ Centro de Investigação Interdisciplinar Egas Moniz (CiiEM), Instituto Universitário Egas Moniz (IUEM), Caparica, Portugal
\end{abstract}

\section{OPEN ACCESS}

Edited by:

Jasminka Z. llich,

Florida State University, United States

Reviewed by:

Jenny Georgina Turcott,

National Institute of Cancerology

(INCAN), Mexico

Daniela Caetano Gonçalves,

Federal University of São Paulo, Brazil

${ }^{*}$ Correspondence:

David da Silva Dias

daviddias_77@hotmail.com

tORCID:

David da Silva Dias orcid.org/0000-0002-4806-691X

Carolina Trabulo

orcid.org/0000-0001-5889-085X

Beatriz Gosálbez

orcid.org/0000-0002-0122-4570

Paula Ravasco

orcid.org/0000-0002-6056-8269

Specialty section:

This article was submitted to

Clinical Nutrition,

a section of the journal

Frontiers in Nutrition

Received: 24 February 2021 Accepted: 09 December 2021

Published: 27 January 2022

Citation:

da Silva Dias D, Machado M, Trabulo C, Gosálbez B and Ravasco $P$ (2022) Impact of Body Composition on Prognosis and Dose-Limiting Toxicities on Metastatic Colorectal

Cancer. Front. Nutr. 8:671547. doi: 10.3389/fnut.2021.671547
Sarcopenia is a progressive skeletal muscle disease, often present in oncological patients, that is associated with multiple adverse events such as worse prognosis, physical performance, and quality of life. Body composition evaluation by CT crosssection at the L3 vertebrae region appears to be a precise method to quantify skeletal muscle. The optimal cut-off for the definition of sarcopenia is not yet established, therefore the incidence of sarcopenia varies according to different studies. The main goal was to evaluate the presence of sarcopenia in patients with metastatic colorectal cancer ( $\mathrm{mCRC}$ ) and its impact on overall survival (OS) and dose-limiting toxicities (DLT). A retrospective cohort study of 178 patients with $\mathrm{mCRC}$ under first-line chemotherapy (ChT) in association with target therapy, in two hospital units, between January 2015 and December 2018. Skeletal mass area (SMA) was quantified with the NIH ImageJ software in CT cross-sectional images at the L3 vertebrae region. Statistical analysis was performed with IBM SPSS v25 software https://www.ibm.com/analytics/spss-statisticssoftware. The median age was 62 (SD \pm 11 ) years old, $65 \%$ were men and $62.9 \%$ had an Eastern Cooperative Oncology Group (ECOG) performance status of 0. The cut-off value was established based on ROC analysis, with sarcopenia defined as $\mathrm{SMI}<49.12$ $\mathrm{cm}^{2} / \mathrm{m}^{2}$ for men and $<35.85 \mathrm{~cm}^{2} / \mathrm{m}^{2}$ for women. Despite the mean body mass index $(\mathrm{BMI})$ of $25.71( \pm 4.71) \mathrm{kg} / \mathrm{m}^{2}$, half of the patients presented sarcopenia. In a multivariate analysis using a Cox regression model, an association was observed between OS and higher ECOG PS ( $p=0.014$; HR 5.46, CI 95\% [1.42-21.10]), neutrophil-to-lymphocyte ratio $(N L R)>2.80(p=0.038 ; \mathrm{HR} 2.20, \mathrm{Cl} 95 \%[1,05-4.62])$, and sarcopenia $(p=0.01$; HR 4.73, Cl 95\% [1.85-12.09]). Additionally, in a logistic regression model, age $(p=$ 0.014; OR 1.09, IC 95\% [1.02-1.16]) and sarcopenia ( $p=0.030$, OR 4.13, IC 95\% [1.15-14.8]) were associated with higher incidence of DLT. The CT evaluation of the body composition at the L3 region allows for the quantification of sarcopenia, providing prognostic information and predictive value of $D L T$ in patients with $\mathrm{MCRC}$, although the establishment of optimal cut-off values are required for implementation in clinical practice. A multimodal strategy to delay muscle waste should be considered in these patients.

Keywords: body composition, body mass index, skeletal muscle index, sarcopenia, metastatic colorectal cancer, dose limiting toxicities, neutrophil-to-lymphocyte ratio, systemic inflammation 


\section{INTRODUCTION}

Colorectal cancer is the second most diagnosed cancer in Europe with 499,000 new cases in 2018 and the second with the highest mortality accounting for approximately 242,000 deaths (1). In the last two decades, the incidence has been increasing, meanwhile, patients with metastatic colorectal cancer (mCRC) have presented improvements in survival, possibly explained by the creation of multidisciplinary teams to provide the best therapeutic decision, as well as the new approaches to oligometastatic disease and new systemic target therapies (2).

Body composition can be evaluated by several methods such as anthropometric measurements as well as electric bioimpedance analysis (BIA). Although these are non-invasive, inexpensive, and reproducible, they lack the precision of other methods such as dual-energy $x$-ray absorptiometry (DXA), CT, and MRI (3). DXA has great accuracy to detect body composition, however, it is not used routinely in oncologic patients. CT scan has been a promising and reliable method to detect body composition in patients with cancer, with no extra costs nor toxicities as it is already performed routinely at diagnosis and follow-up. It appears to be especially efficient at detecting the skeletal muscle area (SMA) at the cross-section of the L3 vertebrae region, allowing the quantification of muscle mass with great precision when correlated to DXA (4).

Patients with mCRC present sustained body weight (BW) loss and muscle wasting, explained by several factors such as insufficient caloric and protein intake, antineoplastic treatments, and metabolic alterations secondary to chronic systemic inflammation and neoplastic cachexia. These complex processes promote alterations in the body composition of oncologic patients, including sarcopenia (5). Sarcopenia derives from the Greek words for flesh (sarx) and loss (penia) and has been recently considered a disease on ICD-10-CM (M62.84) (6). It has been challenging to define sarcopenia, although many expert groups have addressed this issue such as the European Working Group on Sarcopenia in Older People (EWGSOP) $(7,8)$, International Working Group in Sarcopenia (9), and Asian Working Group for Sarcopenia (10). In the last consensus of EWGSOP, sarcopenia has been defined as a progressive and generalized skeletal muscle disorder associated with an increased likelihood of adverse outcomes including falls, fractures, physical disability, and mortality. For diagnosis purposes, sarcopenia is probable if low muscle strength is detected, although diagnosis is only confirmed with the presence of low muscle quantity or quality. Despite considering CT evaluation a useful method to quantify sarcopenia and expected to be more widely used in the future, no cut-off values were established (7). The incidence of sarcopenia in mCRC varies depending on the cut-off applied, race and gender, although it can be as high as $71 \%$ (11). Sarcopenia has been associated with reduced overall survival (12) and quality of life (13) as well as more toxicities (14), and increased costs for the institution and health system $(15,16)$. In the present study, the incidence of sarcopenia will be procured in this population with $\mathrm{mCRC}$ and analyzed whether CT-defined sarcopenia at the L3 level could predict overall survival (OS) and dose-limiting toxicities (DLT).

\section{MATERIALS AND METHODS}

\section{Patients and Procedures}

Retrospective cohort study based on data collected in medical records of 178 patients with colorectal carcinoma confirmed histologically, stage IV, under first-line metastatic chemotherapy (ChT) in association with target therapy such as epidermal growth factor receptor inhibitor, panitumumab, or vascular endothelial growth factor inhibitor, bevacizumab. Patients were identified based on the Regional Oncological Registry (ROR) in two hospital units at Centro Hospitalar Universitário do Algarve (CHUA), in Portugal, between January 2015 and December 2018. This study was conducted according to the guidelines of the Declaration of Helsinki and was approved by the Ethics committee for health care of Centro Hospitalar Universitário do Algarve, with a waiver for informed consent (Protocol UAIF 85/2020, approved in 26.08.2020). The data collected included demographic variables (gender, age, comorbidities, performance status [PS], and anthropometric measurements such as BW and height), variables related to the tumor (colon or rectal cancer, colon laterality, RAS mutation status, organs affected by metastasis), related to inflammation (neutrophils and lymphocytes), and treatment (treatment protocol applied, metastasectomy and toxicities according to common terminology criteria for adverse events-CTCEA v5.0).

The CT scan images at diagnosis of the metastatic disease of 81 of the 178 patients were analyzed using the National Institute of Health ImageJ software https://imagej.nih.gov/ij/download.html by a single observer. SMA at the cross-sectional area of L3 region was identified and delineated by its anatomic features using the hardware Wacom One https://www.wacom.com/enus/products/pen-tablets/one-by-wacom. The muscles included were psoas major, quadratus lumborum, erector spinae, latissimus dorsi, abdominal oblique muscles, and rectus abdominis. SMA was quantified using pre-established-29 to 150 Hounsfield units (HU) range for skeletal muscle and was expressed in square centimeters $\left(\mathrm{cm}^{2}\right)$. The skeletal muscle index (SMI) was calculated by dividing the SMA by the square of the height and the results were reported as square centimeters per square meters $\left(\mathrm{cm}^{2} / \mathrm{m}^{2}\right)$.

\section{Outcomes}

The primary endpoint was OS, defined as the time between the beginning of the 1 st line palliative treatment and the event of death. The secondary endpoint was DLT, defined as severe toxicities requiring dose reduction, delay, and/or discontinuation of oncological drugs under first-line treatment. Discontinuation of the drug due to disease progression was not accounted for DLT definition.

\section{Statistical Analysis}

Statistical analysis was performed with IBM SPSS Statistics $v 25$ software. Treatment of missing data was based on the listwise deletion method. Continuous variables were reported as means and their standard deviation. Differences in means with normal distribution were analyzed with the $t$-student test for two independent samples. Continuous variables that do not 
TABLE 1 | Basal characteristics.

\begin{tabular}{|c|c|}
\hline Variable & Total $n=178$ \\
\hline Age & $62.33 \pm 10.57$ \\
\hline \multicolumn{2}{|l|}{ ECOG PS } \\
\hline 0 & $112-62.9 \%$ \\
\hline 1 & $41-23.0 \%$ \\
\hline$\geq 2$ & $25-14.1 \%$ \\
\hline \multicolumn{2}{|l|}{ Diabetes mellitus } \\
\hline 0 & $156-87.6 \%$ \\
\hline 1 & $22-12.4 \%$ \\
\hline \multicolumn{2}{|l|}{ Laterality } \\
\hline Left colon & $68-53.5 \%$ \\
\hline Right colon & $59-46.5 \%$ \\
\hline \multicolumn{2}{|l|}{ Metastasis (M1) } \\
\hline Liver & $138-77.5 \%$ \\
\hline Lung & $51-28.7 \%$ \\
\hline Peritoneum & $35-19.7 \%$ \\
\hline \multicolumn{2}{|l|}{ Metastasectomy } \\
\hline 0 & $157-88.2 \%$ \\
\hline 1 & $21-11.8 \%$ \\
\hline \multicolumn{2}{|l|}{ Treatment } \\
\hline Panitumumab & $65-36.5 \%$ \\
\hline Bevacizumab & $113-63.5 \%$ \\
\hline \multicolumn{2}{|l|}{ Gender } \\
\hline Male & $117-65.7 \%$ \\
\hline Female & $61-34.3 \%$ \\
\hline \multicolumn{2}{|l|}{ Smoker } \\
\hline 0 & $145-81.5 \%$ \\
\hline 1 & $33-18.5 \%$ \\
\hline \multicolumn{2}{|l|}{ Histology } \\
\hline Colon cancer & $127-71.3 \%$ \\
\hline Rectal cancer & $51-28.7 \%$ \\
\hline \multicolumn{2}{|l|}{ Ras mutation } \\
\hline Ras wild type & $103-57.9 \%$ \\
\hline Ras mutated & $63-35.4 \%$ \\
\hline Unknown & $12-6.7 \%$ \\
\hline \multicolumn{2}{|l|}{ M1 in organ sites } \\
\hline 1 & $112-62.9 \%$ \\
\hline$\geq 2$ & $66-37.1 \%$ \\
\hline \multicolumn{2}{|l|}{ Treatment ${ }^{*}$} \\
\hline $\mathrm{F}+\mathrm{O}+\mathrm{T}$ & $97-54.5 \%$ \\
\hline$F+I+T$ & $67-37.6 \%$ \\
\hline$F+\pi$ & $10-5.6 \%$ \\
\hline $\mathrm{F}+\mathrm{O}+\mathrm{I}+\pi$ & $4-2.2 \%$ \\
\hline \multicolumn{2}{|c|}{ Initial body weight, BMI, SMI } \\
\hline Variable & Total \\
\hline Mean BW (kg) $(n=178)$ & $71.12 \pm 15.9$ \\
\hline Male & $77.05 \pm 14.3$ \\
\hline Female & $59.55 \pm 10.78$ \\
\hline \multicolumn{2}{|l|}{ BMI groups $(n=178)$} \\
\hline$<18.5 \mathrm{~kg} / \mathrm{m}^{2}$ & $7-3.9 \%$ \\
\hline $18.5-24.9 \mathrm{~kg} / \mathrm{m}^{2}$ & $54-30.3 \%$ \\
\hline
\end{tabular}

(Continued)
TABLE 1 | Continued

\begin{tabular}{lc}
\hline Variable & Total $\boldsymbol{n}=\mathbf{1 7 8}$ \\
\hline $25-29.9 \mathrm{~kg} / \mathrm{m}^{2}$ & $53-29.8 \%$ \\
$>30 \mathrm{~kg} / \mathrm{m}^{2}$ & $33-18.5 \%$ \\
Mean BMI $\left.\mathbf{( k g} / \mathbf{m}^{2}\right)(n=178)$ & $25.71 \pm 4.71$ \\
Male & $26.85 \pm 4.72$ \\
Female & $23.64 \pm 3.97$ \\
Mean SMI $\left(\mathbf{c m}^{2} / \mathbf{m}^{2}\right)(n=81)$ & $44.16 \pm 10.80$ \\
Male $(n=51)$ & $49.18 \pm 9.63$ \\
Female $(n=30)$ & $35.61 \pm 6.46$
\end{tabular}

${ }^{*}$ F, Fluoropyrimidine; O, Oxaliplatin; I, Irinotecan; TT, Target therapy.

respond to parametric parameters were analyzed with MannWhitney U-test. For the association of categorical variables, the chi-square test $\left(\mathrm{X}^{2}\right)$ was performed. The definition of cut-off points for sarcopenia (SMI) and systemic inflammation (NLRNeutrophil-to-lymphocyte ratio) was obtained by receiver operating characteristic (ROC) analyses. Survival analyses were obtained by the Kaplan-Meier method with the log-rank test. Lastly, with the intention of reducing Type-I error, a multivariate analysis with Cox regression model was performed with variables that present association with OS on a univariate level, and a multivariate analysis with logistic regression model was performed on variables associated with DLT. The results were reported with a hazard ratio (HR) or odds ratio (OR) as a measure of association and confidence interval (CI) of $95 \%$.

\section{RESULTS}

\section{Basal Characteristics}

A total of 178 patients were analyzed, 65 underwent treatment with ChT plus panitumumab (ChT-Pan) and 113 with ChT plus bevacizumab (ChT-Bev). The mean age was $62(\mathrm{SD} \pm 11)$ years old, $65.7 \%$ of patients were male and $62.9 \%$ of individuals had an ECOG PS of 0 . The RAS mutation was present in at least $35 \%$. The most common site of metastasis was the liver (77.5\%) and metastasectomy on oligometastatic patients was performed in 21 patients $(11.8 \%)$. The mean $\mathrm{BW}$ was $71.12(\mathrm{SD} \pm 15.9) \mathrm{kg}$ and the mean body mass index (BMI) was $25.71(\mathrm{SD} \pm 4.71)$ $\mathrm{kg} / \mathrm{m}^{2}$. SMI was evaluated in $45.5 \%(n=81)$ of the population and sarcopenia was defined in this population of patients with mCRC as SMI $<49.12 \mathrm{~cm}^{2} / \mathrm{m}^{2}$ for men and $<35.85 \mathrm{~cm}^{2} / \mathrm{m}^{2}$ for women. Despite $61.1 \%$ of patients having normal weight or were overweight, and $18.5 \%$ were obese, sarcopenia was present in $49.4 \%$ of patients. Sarcopenic obesity, defined as the presence of sarcopenia and BMI $\geq 30 \mathrm{~kg} / \mathrm{m}^{2}$, was observed in 3 patients. Basal characteristics of the population can be seen in greater detail in Table $\mathbf{1 .}$

\section{Outcomes and Toxicities}

The outcomes varied depending on the treatment applied. In thePan treatment group the overall response rate (ORR) was 64.6\%, the progression-free survival (PFS) was 13 months, and the OS, 21 months. In the ChT-Bev group, the ORR was 59.3\%, PFS 10 months, and OS 19 months. 


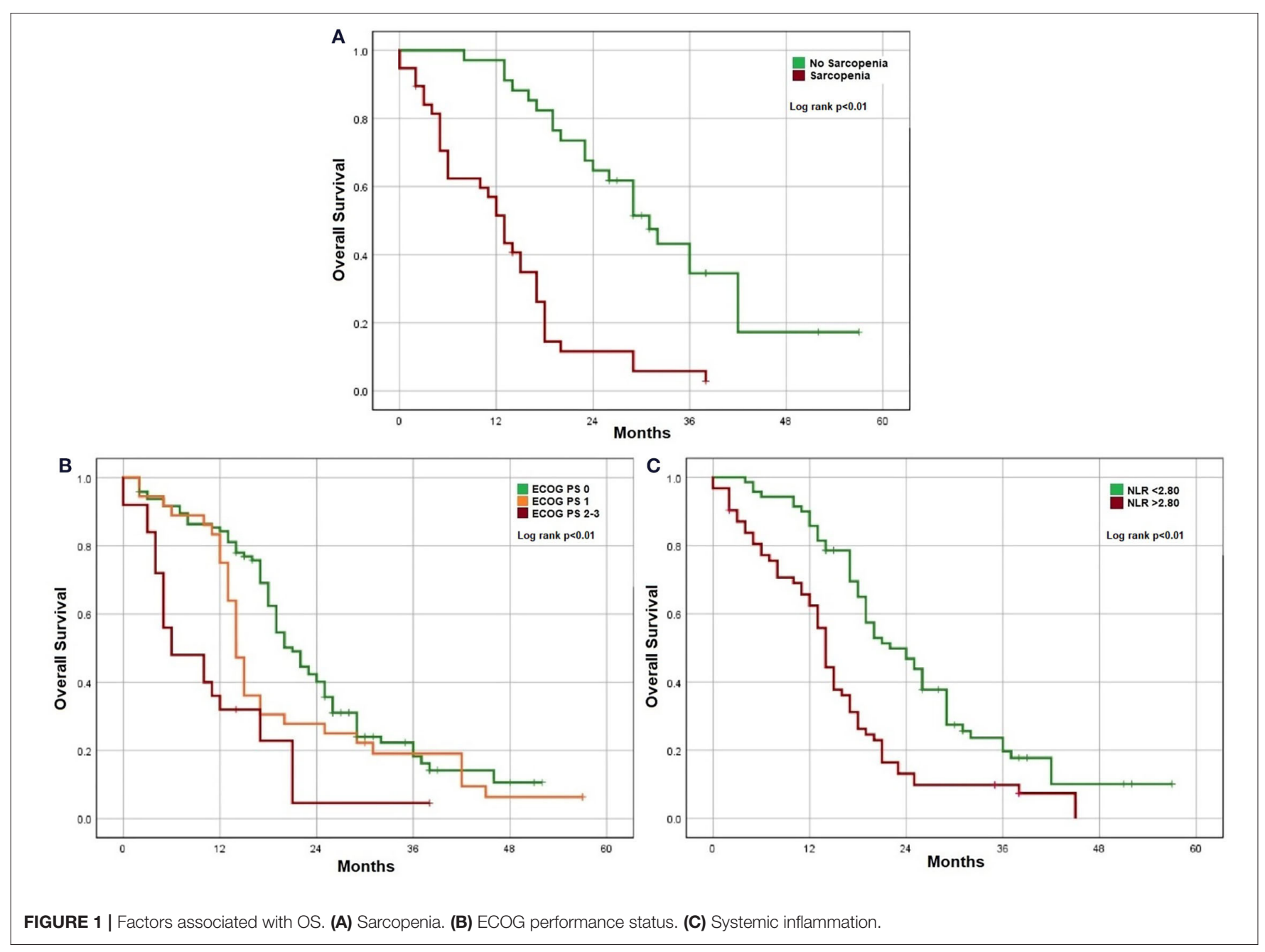

Any grade toxicities in the ChT-Pan treatment group were present in $58(89.2 \%)$ patients. Severe toxicities (grade 3 and 4, CTCEA v5.0) were present in $26(40 \%)$, mainly cutaneous in $14(21.5 \%)$, hematological in $7(10.8 \%)$, gastrointestinal in $4(6.2 \%)$ and peripheral neuropathy in 3 (4.6\%). Any grade toxicities in the ChT-Bev treatment group were present in $87(77 \%)$ patients. Severe toxicities in 57 (50.4\%), mainly hematological in 27 (23.9\%), gastrointestinal in 15 (13.2\%), and peripheral neuropathy in $6(5.3 \%)$. The incidence of higher severe hematological and gastrointestinal toxicities in the ChTBev group compared with the ChT-Pan group may be, in part, explained by using a triplet chemotherapy protocol in 4 patients. DLT were present in 43 patients (66.2\%) of the ChT-Pan group and in $66(58.4 \%)$ in the ChT-Bev. Two toxic deaths were observed in the ChT-Bev group due to febrile neutropenia and none in the ChT-Pan treatment group.

\section{Factors Affecting Overall Survival and Dose Limiting Toxicities}

For the investigation of factors associated with OS and DLT, only unresectable mCRC patients were assessed $(n=157)$. Clinically relevant factors were analyzed in a univariate analysis and factors that demonstrate significant association $(p<0.05 \%)$ with this method were posteriorly analyzed in a multivariate model. In a multivariate analysis using a Cox regression model, higher ECOG PS, systemic inflammation with NLR $>2.80$, and presence of sarcopenia were associated with lower OS (Figure 1 and Table 2). Using a logistic regression model, age and sarcopenia were associated with increased DLT. Patients with sarcopenia presented more DLT in comparison with patients without it (76.3 vs. $44.1 \%)$. Only 3 patients in this sample presented sarcopenic obesity, remarkably all of them presented DLT.

\section{DISCUSSION}

Body composition evaluation by CT scan could be performed in patients with cancer, as they undergo this exam routinely at diagnosis and follow-up. The most used software in the literature is the commercially available and validated Slice-OMatic. NIH ImageJ software appears to have the same precision detecting SMA (17). This method, although it can be performed 
TABLE 2 | Factors influencing OS and DLT.

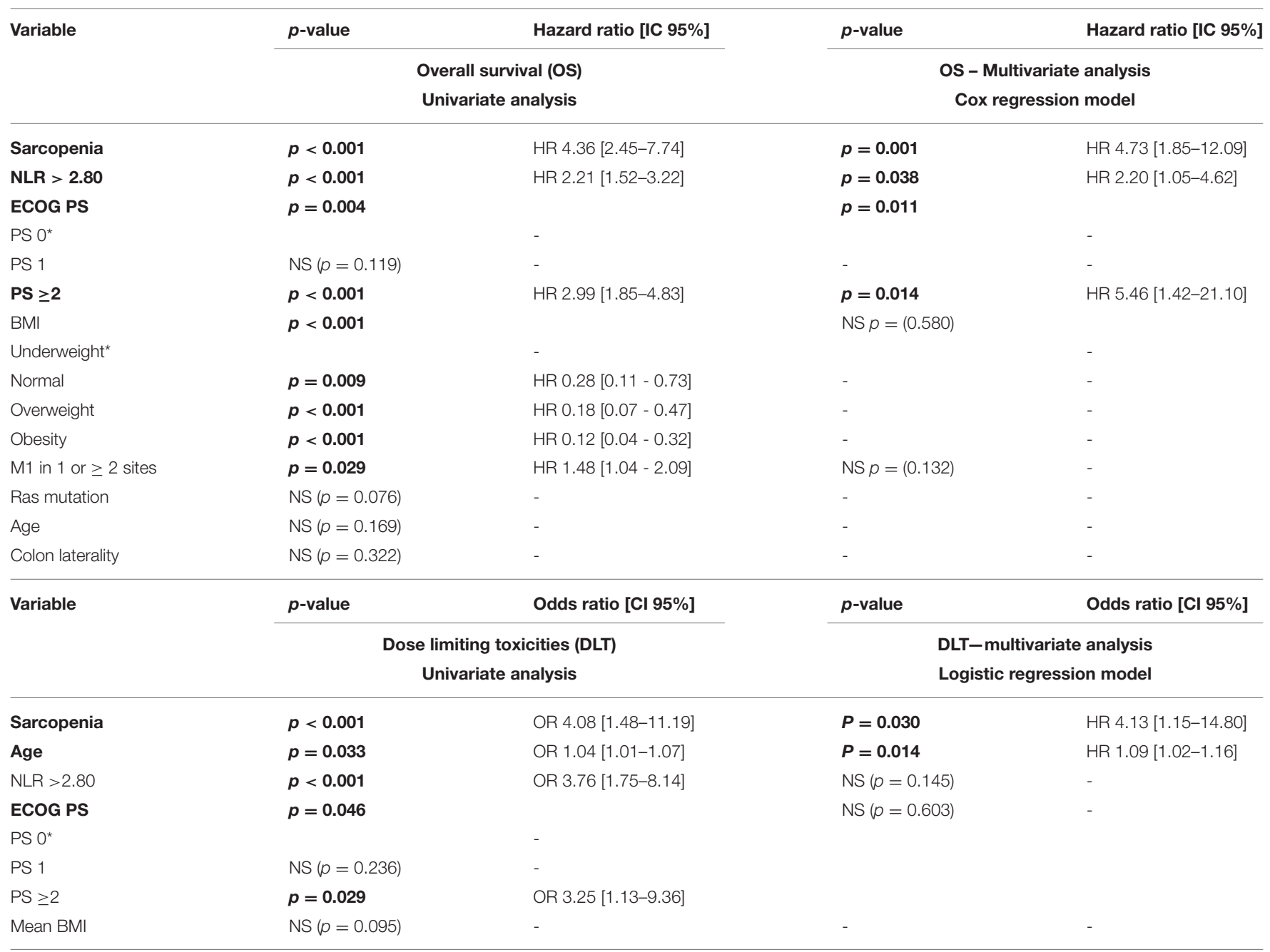

p-values and variables that are statistically significant in a multivariate analysis.

in other cross-section regions, is usually performed at the crosssection of the L3 vertebra, as there is a close correlation between muscle and fat areas and corresponding tissue volumes, as such, it is considered a reference point for both sexes (18). There are no established cut-off values to define sarcopenia with this method. Some studies apply the cut-off used in Prado et al. study (19), defined as SMI $<52.40 \mathrm{~cm}^{2} / \mathrm{m}^{2}$ for men and $<38.50 \mathrm{~cm}^{2} / \mathrm{m}^{2}$ for women. In Asian patients, the cutoff are usually lower as $<36 \mathrm{~cm}^{2} / \mathrm{m}^{2}$ for men and $<29$ $\mathrm{cm}^{2} / \mathrm{m}^{2}$ for women (20). The authors believe these cut-off values presented have some degree of heterogeneity, including population with different tumors, with different biological activity as well as different tumor staging. Similarly, patients with cancer living in different locations worldwide, present different body composition, as seen in the above examples. This heterogeneity is a major hindrance in the implementation of this method in clinical practice. In this study, the cut-off values for sarcopenia for this specific Portuguese population with $\mathrm{mCRC}$ were SMI $<49.12 \mathrm{~cm}^{2} / \mathrm{m}^{2}$ for men and $<35.85$ $\mathrm{cm}^{2} / \mathrm{m}^{2}$ for women. The prevalence of sarcopenia was $49.4 \%$ while the mean BMI was $25.71 \mathrm{~kg} / \mathrm{m}^{2}$, which suggests that patients may be sarcopenic even though they don't present visible signs of malnutrition $(21,22)$. An example can be observed in Figure 2 .

In this study, sarcopenic patients showed worse OS, in line with the consistent growing evidence of the prognostic value of this method (23-25). It was also able to predict DLT, which goes in accordance to the literature $(21,26)$, although there is still some debate on this matter, as in the case of CAIRO 3 population study, sarcopenia at diagnosis was not predictive of DLT, only a loss $>2 \%$ of SMI in the 3 months follow up was a predictor of DLT (22). Sarcopenic obesity is a specific entity, associated with several health-related risks, particularly related to increased toxicities and reduced OS in oncological patients. In this study only 3 patients presented sarcopenic obesity, interestingly all of them developed DLT $(19,27)$. It raises the question of whether the conventional body surface area is the most appropriate method of dosing cytotoxic drugs. A hypothesis for the excess of toxicity in this population suggests that many ChT drugs are hydrophilic and consequently, patients receive a higher absolute 

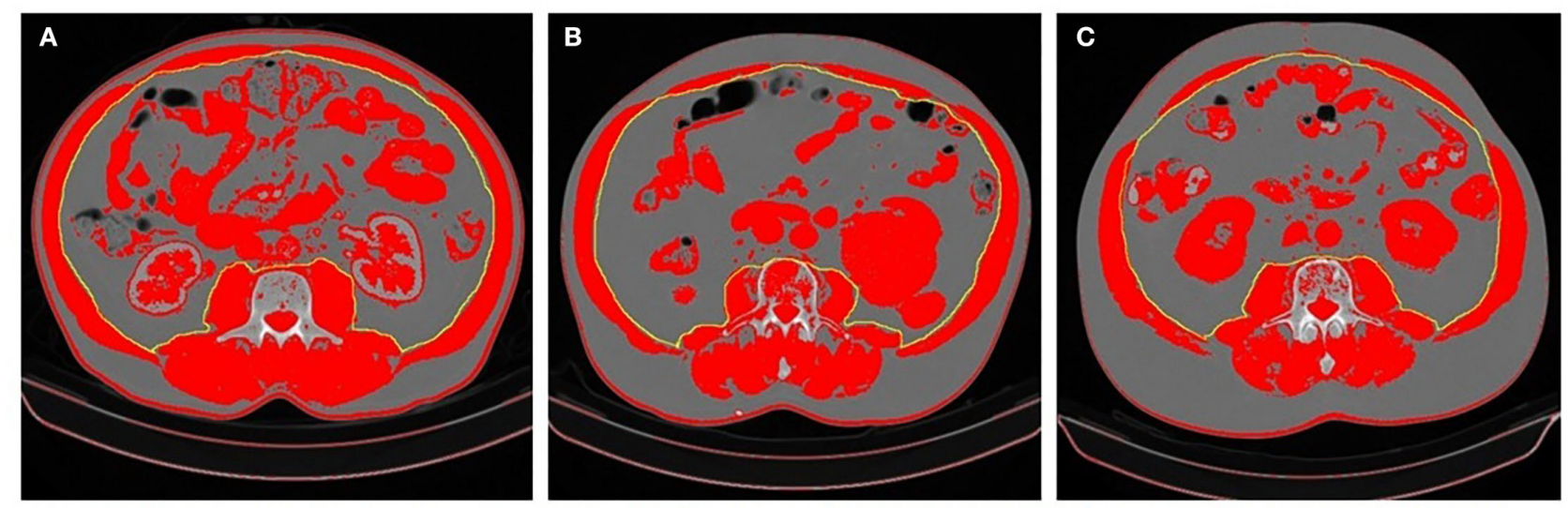

FIGURE 2 | Differences in body composition in three patients. (A) Patient overwright (BMl $\left.28.13 \mathrm{~kg} / \mathrm{m}^{2}\right)$ with no sarcopenia (SMl $\left.62.80 \mathrm{~cm}{ }^{2} / \mathrm{m}^{2}\right)$; (B) Patient overwright (BMl $28.70 \mathrm{~kg} / \mathrm{m}^{2}$ ) with sarcopenia (SMl $\left.45.40 \mathrm{~cm}^{2} / \mathrm{m}^{2}\right)$; (C) Patient with sarcopenic obesity (BMI $34.51 \mathrm{~kg} / \mathrm{m}^{2}$ and SMI $\left.46.10 \mathrm{~cm} / \mathrm{m}^{2}\right)$. Patients (B,C) presented DLT. The areas in red represent values between -29 and $+150 \mathrm{HU}$. The SMA was determined based on the area of the psoas major, quadratus lumborum, erector spinae, latissimus dorsi, abdominal oblique muscles, and rectus abdominis muscles. SMI was calculated by the SMA/height ${ }^{2}$.

dose while presenting a reduced volume of distribution, leading to higher dose concentrations and increased toxicities $(27,28)$. Sarcopenia identified by CT image at the L3 region appears to be more precise than anthropometric measurements for prognosis and prediction of DLT in patients with MCRC.

Interventions in a late phase of the disease usually are refractory to any treatment modality, therefore, early identification of sarcopenic patients is of utmost importance to elaborate a personalized multimodal approach with nutritional intervention and a physical exercise plan. This approach should be based on disease burden, intent of treatment, patient's physical performance, and desires (29). This personalized approach is crucial, considering that Portuguese patients with mCRC usually present insufficient mean caloric and protein intake, $20.1 \mathrm{Kcal} / \mathrm{kg}$ and $0.85 \mathrm{~g} / \mathrm{kg}$ respectively, much lower than the recommendations of $25-30 \mathrm{Kcal} / \mathrm{kg}$ and $1.5 \mathrm{~g} / \mathrm{kg}$ by ESPEN $(30,31)$.

As a retrospective study, several limitations are present and should be considered as it relies on data not primarily meant for research. Missing data were present and treated accordingly, some patients had no CT scan images in our institution database as they were performed in an external institution, which may introduce selection bias.

\section{CONCLUSION}

Sarcopenia identified by CT evaluation at the L3 region was associated with significantly worse prognosis and increased doselimiting toxicities in mCRC. The establishment of optimal cut-off

\section{REFERENCES}

1. Globocan 2018. Incidence and Mortality in Europe. (2018). Available online at: https://gco.iarc.fr/today/online-analysis- pie? $\mathrm{v}=2018 \&$ mode $=$ cancer\& values is still a barrier to implementing this method in clinical practice, and as such, studies with less heterogeneity should be conducted. Half the patients with mCRC presented sarcopenia, and an early introduction of a multimodal strategy to prevent muscle waste should be considered.

\section{DATA AVAILABILITY STATEMENT}

The raw data supporting the conclusions of this article will be made available by the authors, without undue reservation.

\section{ETHICS STATEMENT}

The studies involving human participants were reviewed and approved by Comissão de Ética para a Saúde. Written informed consent for participation was not required for this study in accordance with the national legislation and the institutional requirements.

\section{AUTHOR CONTRIBUTIONS}

DD performed the literature research, the statistical analysis, the interpretation of data, and wrote the draft of this manuscript. MM extracted L3-CT scan images and added valuable information. CT critically reviewed the document and added valuable information. BG critically reviewed the document and added valuable information. PR critically reviewed the document and added valuable information. All authors have read and agreed to the published version of the manuscript. 
2. Van Cutsem E, Cervantes A, Adam R, Sobrero A, Van Krieken J, Aderka D, et al. ESMO consensus guidelines for the management of patients with metastatic colorectal cancer. Ann Oncol. (2016) 27:1386422. doi: 10.1093/annonc/mdw235

3. Hilmi M, Jouinot A, Burns R, Pigneur F, Mounier R, Gondin J, et al. Body composition and sarcopenia: The next-generation of personalized oncology and pharmacology? Pharmacol Ther. (2019) 196:135-59. doi: 10.1016/j.pharmthera.2018.12.003

4. Mourtzakis M, Prado CMM, Lieffers JR, Reiman T, McCargar LJ, Baracos VE, et al. practical and precise approach to quantification of body composition in cancer patients using computed tomography images acquired during routine care. Appl Physiol Nutr Metab. (2008) 33:997-1006. doi: 10.1139/H08-075

5. Argilés JM, Busquets S, Stemmler B, López-Soriano FJ. Cancer cachexia: understanding the molecular basis. Nat Rev Cancer. (2014) 14:75462. doi: $10.1038 / \mathrm{nrc} 3829$

6. Anker SD, Morley JE, von Haehling S. Welcome to the ICD10 code for sarcopenia. J Cachexia Sarcopenia Muscle. (2016) 7:512-4. doi: 10.1002/jcsm.12147

7. Cruz-Jentoft AJ, Bahat G, Bauer J, Boirie Y, Bruyere O, Cederholm T, et al. Sarcopenia: revised European consensus on definition and diagnosis. Age Ageing. (2019) 48:16-31. doi: 10.1093/ageing/afz046

8. Cruz-Jentoft AJ, Baeyens JP, Bauer JM, Boirie Y, Cederholm T, Land F, et al. Sarcopenia: European consensus on definition and diagnosis: Report of the European Working Group on Sarcopenia in Older People. Age Ageing. (2010) 39:412-23. doi: 10.1093/ageing/afq034

9. Fielding RA, Vellas B, Evans WJ, Bhasin S, Morley J, Newman A, et al. Sarcopenia: an undiagnosed condition in older adults. Current consensus definition: prevalence, etiology, and consequences international working group on sarcopenia. J Am Med Dir Assoc. (2011) 12:24956. doi: 10.1016/j.jamda.2011.01.003

10. Chen L-K, Liu L-K, Woo J, Assantachai P, Auyeung T, Habyah $\mathrm{K}$, et al. Sarcopenia in Asia: consensus report of the Asian Working Group for sarcopenia. J Am Med Dir Assoc. (2014) 15:95-101. doi: 10.1016/j.jamda.2013.11.025

11. Cherin P, Voronska E, Fraoucene N, de Jaeger C. Prevalence of sarcopenia among healthy ambulatory subjects: the sarcopenia begins from 45 years. Aging Clin Exp Res. (2014) 26:137-46. doi: 10.1007/s40520-013-0132-8

12. da Cunha LP, Silveira MN, Mendes MCS, Costa F, Macedo L, Siqueira N, et al. Sarcopenia as an independent prognostic factor in patients with metastatic colorectal cancer: a retrospective evaluation. Clin Nutr ESPEN. (2019) 32:10712. doi: 10.1016/j.clnesp.2019.04.004

13. Nipp RD, Fuchs G, El-Jawahri A, Mario J, Troschel F, Greer J, et al. Sarcopenia is associated with quality of life and depression in patients with advanced cancer. Oncologist. (2018) 23:97-104. doi: 10.1634/theoncologist.2017-0255

14. Gökyer A, Küçükarda A, Köstek O, Hacioglu MB, Sunal BS, Demircan NC, et al. Relation between sarcopenia and dose-limiting toxicity in patients with metastatic colorectal cancer who received regorafenib. Clin Transl Oncol. (2019) 21:1518-23. doi: 10.1007/s12094-019-02080-4

15. Lieffers JR, Bathe OF, Fassbender $K$, Winget $M$, Baracos VE. Sarcopenia is associated with postoperative infection and delayed recovery from colorectal cancer resection surgery. Br J Cancer. (2012) 107:931-6. doi: 10.1038/bjc.2012.350

16. Sousa AS, Guerra RS, Fonseca I, Pichel F, Ferreira S, Amaral TF. Financial impact of sarcopenia on hospitalization costs. Eur J Clin Nutr. (2016) 70:104651. doi: 10.1038/ejcn.2016.73

17. Irving BA, Weltman JY, Brock DW, Davis CK, Gaesser GA, Weltman A, et al. ImageJ and slice-O-matic computed tomography imaging software to quantify soft tissue. Obesity. (2007) 15:370-6. doi: 10.1038/oby.2007.573

18. Schweitzer L, Geisler C, Pourhassan M, Braun W, Gluer C, Bosy-Wesphal A, et al. What is the best reference site for a single MRI slice to assess whole-body skeletal muscle and adipose tissue volumes in healthy adults? Am J Clin Nutr. (2015) 102:58-65. doi: 10.3945/ajcn.115.111203

19. Prado CM, Lieffers JR, McCargar LJ, Reiman T, Sawyer M, Martin L, et al. Prevalence and clinical implications of sarcopenic obesity in patients with solid tumours of the respiratory and gastrointestinal tracts: a population-based study. Lancet Oncol. (2008) 9:629-35. doi: 10.1016/S1470-2045(08)70153-0

20. Iritani S, Imai K, Takai K, Hanai T, Ideta T, Miyazaki T, et al. Skeletal muscle depletion is an independent prognostic factor for hepatocellular carcinoma. $J$ Gastroenterol. (2015) 50:323-32. doi: 10.1007/s00535-014-0964-9

21. Barret M, Antoun S, Dalban C, Malkad D, Mansourbakhte T, Zaananf A, et al. Sarcopenia is linked to treatment toxicity in patients with metastatic colorectal cancer. Nutr Cancer. (2014) 66:583-9. doi: 10.1080/01635581.2014.894103

22. Kurk S, Peeters P, Stellato R, Dorresteijn B, Jong P, Jourdan M, et al. Skeletal muscle mass loss and dose-limiting toxicities in metastatic colorectal cancer patients. J Cachexia Sarcopenia Muscle. (2019) 10:80313. doi: $10.1002 /$ jcsm. 12436

23. Kazemi-Bajestani SMR, Mazurak VC, Baracos V. Computed tomographydefined muscle and fat wasting are associated with cancer clinical outcomes. Semin Cell Dev Biol. (2016) 54:2-10. doi: 10.1016/j.semcdb.2015. 09.001

24. Blauwhoff-Buskermolen S, Versteeg KS, de van der Schueren MAE, Braver $\mathrm{N}$, Berkhof K, Langius J, et al. Loss of muscle mass during chemotherapy is predictive for poor survival of patients with metastatic colorectal cancer. J Clin Oncol. (2016) 34:1339-44. doi: 10.1200/JCO.2015.63.6043

25. van Vledder MG, Levolger S, Ayez N, Verhoef C, Tran TCK, IJzermans JNM. Body composition and outcome in patients undergoing resection of colorectal liver metastases. Br J Surg. (2012) 99:550-7. doi: 10.1002/bjs.7823

26. Cespedes Feliciano EM, Lee VS, Prado CM, Meyerhardt J, Alexeeff S, Kroenke C, et al. Muscle mass at the time of diagnosis of nonmetastatic colon cancer and early discontinuation of chemotherapy, delays, and dose reductions on adjuvant FOLFOX: the C-SCANS study. Cancer. (2017) 123:4868-77. doi: 10.1002/cncr.30950

27. Baracos VE, Arribas L. Sarcopenic obesity: hidden muscle wasting and its impact for survival and complications of cancer therapy. Ann Oncol. (2018) 29:ii1-9. doi: 10.1093/annonc/mdx810

28. Prado CMM, Baracos VE, McCargar LJ, Mourtzakis M, Mulder $\mathrm{K}$, Reiman T, et al. Body composition as an independent determinant of 5fluorouracil-based chemotherapy toxicity. Clin Cancer Res. (2007) 13:32648. doi: 10.1158/1078-0432.CCR-06-3067

29. Prado CM, Purcell SA, Laviano A. Nutrition interventions to treat low muscle mass in cancer. J Cachexia Sarcopenia Muscle. (2020) 11:36680. doi: $10.1002 /$ jcsm. 12525

30. Madureira EMN. Nutritional Intake, Inflamation and Nutritional Status Evaluation in Oncological Patients. (2015). Available online at: https:// repositorio-aberto.up.pt/bitstream/10216/81346/2/37131.pdf (accessed February, 2020).

31. Arends J, Bachmann P, Baracos V, Barthelemy N, Bertz $H$ Bozzetti $\mathrm{F}$, et al. ESPEN guidelines on nutrition in cancer patients. Clin Nutr. (2017) 36:11-48. doi: 10.1016/j.clnu.2016. 07.015

Conflict of Interest: The authors declare that the research was conducted in the absence of any commercial or financial relationships that could be construed as a potential conflict of interest.

Publisher's Note: All claims expressed in this article are solely those of the authors and do not necessarily represent those of their affiliated organizations, or those of the publisher, the editors and the reviewers. Any product that may be evaluated in this article, or claim that may be made by its manufacturer, is not guaranteed or endorsed by the publisher.

Copyright (c) 2022 da Silva Dias, Machado, Trabulo, Gosálbez and Ravasco. This is an open-access article distributed under the terms of the Creative Commons Attribution License (CC BY). The use, distribution or reproduction in other forums is permitted, provided the original author(s) and the copyright owner(s) are credited and that the original publication in this journal is cited, in accordance with accepted academic practice. No use, distribution or reproduction is permitted which does not comply with these terms. 